Ящук Светлана

кандидат психологических наук, доцент кафедры психологии

Брестского государственного университета им. А.С. Пушкина, г. Брест (Республика Беларусь) http://orcid.org/0000-0002-5886-6136

DOI https://doi.org/10.35619/praprv.v1i15.200

\title{
ОСОБЕННОСТИ ВЫБОРА ЛИЧНОСТЬЮ ЗАЩИТНЫХ МЕХАНИЗМОВ
}

Аннотация. Материаль данной статьи посвящены вопросам стратегии выбора защиттных механизмов личностью в соответствии с особенностями проявленности таких личностных характеристик как нейротизм, психотизм, внутренняя конфликтность, самоотношение. На основе анализа используемых механизмов психологической защиты студентами технического университета и присущих им личностных характеристик выявлены преобладающие стратегии использования защитных механизмов. На основе анализа полученных данных было установлено, что психика каждого человека использует несколько механизмов психологической защиты, причем некоторые механизмы психологической защиты присущи большему количеству людей, а некоторые проявляются реже, при этом количество механизмов психологической защиты и прочент их использования зависит от темперамента, внутренней конфликтности и самообвинения. $B$ исследовании было выявлено, что всем респондентам присущ нейротизм. Было установлено, что невротики используют МПЗ в максимально полном объеме. Респонденть $c$ психотизмом используют их меньше. Все респонденты используют защитный механизм «интеллектуализаџию», что относится к более зрельм защитным механизмам. В данном исследовании выявлен низкий уровень «внутренней конфликтности» и «самообвинения». Полученные результаты позволяют расширить сферу деятельности психологического просвещения и профилактики молодежи в контексте осознания и понимания «личностных» ресурсов.

Ключевые слова: механизмы психологической защиты, защитные механизмы, психологическая защита, личность, эмоциональная устойчивость, темперамент, самоотношение, нейротизм.

Постановка проблемы. В жизни и деятельности человек в настоящее время часто находится в пространстве с негативным воздействием со стороны социальных, профессиональных, экологических и других факторов. Увеличение информационного потока, при этом в большом объёме негативного, нехватка времени, интенсивное общение приводят к тому, что увеличиваются физические и эмоциональные нагрузки на человека, нарушается профессиональная эффективность, вследствие чего развиваются психосоматические заболевания или невротические расстройства. Все эти факты направляют интерес исследователей к изучению природы защитных механизмов и стратегий выбора именно своих «личностных» механизмов защиты, которые помогают человеку жить в столь активном и быстро меняющемся мире.

Любой человек имеет определенную систему психологической защиты, способной обеспечить иммунитет от разрушающих влияний на её личность. Сама сила защиты зависит от врожденных и приобретенных за жизнь психологических особенностей человека и его знаний. Для того чтобы помочь человеку справляться со всеми испытаниями, возникающими в его жизни, открытым остается вопрос: существует ли зависимость между выбором защитных механизмов и темпераментом личности, самоотношением, внутренней конфликтностью и другими факторами, включая внешние.

Анализ современных исследований проблемы. Вопрос выбора механизмов психологической защиты личностью в зависимости от особенностей самой личности 
исследуется в современной отечественной и зарубежной литературе, как со стороны теории, так и практики. На данном этапе существует множество подходов к очерчиванию самого пространства феномена психологическая защита и линий функционирования механизмов психологической защиты. Можно выделить основные направления: психологическая защита личности в условиях неопределенности (Баева, 2008; Аршинов, 2003; Киршбаум, 2000; Мэй; 2001; Хьелл, 2003), психологическая защита личности и здоровье (Котенева, 2008; Лазебная, 2007; Тарабрина, 2008; Егоров, 2007), психологическая защита личности и нравственность (Дубровина, 2008; Ушаков, 2009; Юревич, 2009; Цапенко, 2009; Слободчиков, 2004; МеликПашаев, 2010, Братусь, 2007; Элтоне, 2004), самосознание и защитные механизмы личности (Лапланш, 2000; Понталис, 2000; Грановская, 2006; Никольская, 2006, Соколова, 2007).

Цель работы: изучение стратегий выбора защитных механизмов личности у людей с разным уровнем эмоциональной стабильности личности и разной внутренней конфликтностью.

Процедура исследования. Исследование проводилось на базе УО Брестского государственного политехнического университета. Респондентами выступила группа юношей и девушек 18-20 лет (студенты 2 курса). В исследовании приняло участие 40 человек - 29 юношей и 11 девушек. Участие было добровольным и анонимным. Предварительно перед проведением исследования состоялась ознакомительная встреча со студентами, затем были даны объяснения, как правильно заполнять бланки. В нашем случае половина опрошенных изъявили желание узнать результаты тестирования. Им было предложено оставить телефон для обратной связи в знак благодарности. После обработки данных были созданы отдельные файлы на Google диске для каждого участника с результатами и рекомендациями и отправлены ссылки желающим. В работе использовались следующие методики: «Индекс жизненного стиля» («Life Index Style») (авт. Плутчик-Келлерман-Конте, 1979); «Методику исследования самоотношения» (Пантелеев, 1989); EPQ-R (Айзенк, 1968).

\section{Основные выводы по результатам эмпирического исследования.}

На первом этапе исследования были проанализированы результаты, полученные по трём методикам.

По методике ИЖС Плутчика, было установлено, что в процентном соотношении все защиты используются примерно в равной степени выраженности (от 64\% до 74\%) у респондентов, использующих защиты выше 50\%. По данным Каменской (1999), нормативные значения этой величины для городского населения равны 40-50 \%. ОН3, превышающий 50-процентный рубеж, отражает реально существующие, но неразрешенные внешние и внутренние конфликты. Первоначально все результаты были разделены на три подгруппы: с высоким уровнем использования механизма защиты, со средним и с низким. Было установлено, что ОНЗ выше нормативного значения имеют 21 респондент. Напряженность каждой используемой защиты респондентами распределилась следующим образом: отрицание используют 69\%; вытеснение - 64\%; регрессию - 67\%; компенсацию -74\%; проекцию - 71\%; замещение - 70\%; интеллектуализацию - 70\%; реактивное образование $-71 \%$.

50\% Анализ результатов диагностики по методике ИЖС, показал, что с показателями выше 50\% подавляющее большинство студентов интеллектуализация/рационализация (29 человек) и отрицание (27 человек). Отрицание действует, когда человек не желает чего-то признавать. Интенсивность психологической защиты выступает как показатель интенсивности и тяжести проблемы, которую человек отрицает. Отрицание относят к примитивным психологическим защитам, имеющими дело с границей между «Я» и внешним миром и связаны с довербальной стадией развития и не осознаются личностью.

Интеллектуализация причисляется к вторичным механизмам защиты, более зрелым, которые «работают» с внутренними границами - между Эго, Супер - Эго и Ид или между наблюдающей и переживающей частями Эго.

Рационализация предполагает переосмысление неприятного или неприемлемого поведения и чувства рациональным образом и обесценивание истинных причин поведения. 
Этот защитный механизм предотвращает беспокойство и защищает свою самооценку. Например: студент, который получил очень низкие оценки в тесте, может рационализировать, говоря, что преподаватель намеренно дал ему низкие оценки, потому что он ненавидит его. Также интересны рационализации студентов, когда они объясняют, почему не готовы к экзамену.

Анализ и обобщение полученных результатов по данной методике позволяет нам предположить, что 21 исследуемый имеет неразрешенные внешние и внутренние конфликты, 16 человек «справляются» с жизненными трудностями, и только 3 человека имеют низкий уровень использования психологических защит (табл.1).

Таблица 1.

\section{Использование МПЗ в группе студентов}

\begin{tabular}{|c|c|c|c|c|}
\hline \multirow{2}{*}{\multicolumn{2}{|c|}{ Защитный механизм }} & \multicolumn{3}{|c|}{$\begin{array}{c}\text { Степень встречаемости защитных механизмов } \\
\text { у студентов (в \%, ) }\end{array}$} \\
\hline & & высокий & средний & низкий \\
\hline $\mathrm{A}$ & отрицание & 69 & 46 & 29 \\
\hline B & вытеснение & 64 & 48 & 24 \\
\hline $\mathrm{C}$ & регрессия & 67 & 47 & 24 \\
\hline $\mathrm{D}$ & компенсация & 74 & 46 & 30 \\
\hline $\mathrm{E}$ & проекция & 71 & 46 & 26 \\
\hline $\mathrm{F}$ & замещение & 70 & 46 & 26 \\
\hline $\mathrm{G}$ & интеллектуализация & 70 & 45 & 25 \\
\hline $\mathrm{H}$ & $\begin{array}{l}\text { реактивное } \\
\text { образование }\end{array}$ & 71 & 45 & 16 \\
\hline \multicolumn{2}{|c|}{ Средние показатели } & 70 & 46 & 25 \\
\hline
\end{tabular}

Использование большого количества механизмов психологической защиты (МПЗ) свидетельствует о наличии у людей низкого уровня безопасности. Их внутренний мир находится в состоянии постоянного ожидания неких угроз со стороны окружения и событий такого же плана. Можно предположить, что они имеют низкий уровень осознанности себя, своих внутренних ресурсов.

Анализ результатов по методике МИС (методика исследования самоотношения) Пантилеева выявил то, что лишь 2 респондента имеют повышенный уровень «самообвинения» и 1 человек повышенный уровень «внутренней конфликтности». Это можно увидеть на рисунке 1. Уровень внутренней неустроенности.

\section{Уровень внутренней неустроенности (МПС)}

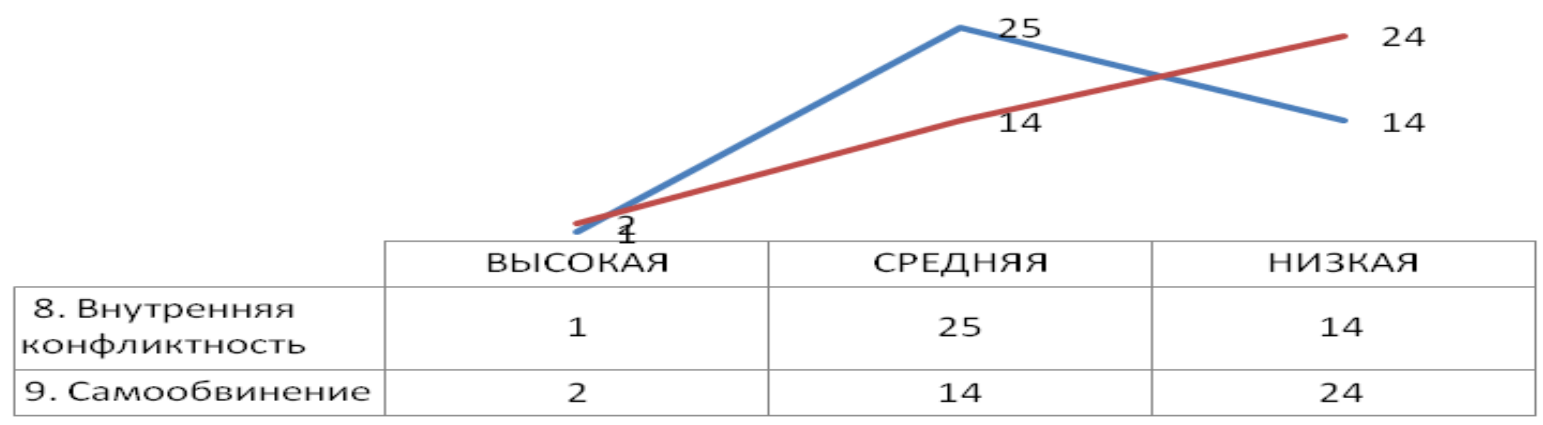

8. Внутренняя конфликтность

9. Самообвинение 
Было установлено, что по шкале «внутренней конфликтности» средние значения имеют 25 человек, и по шкале «самообвинения» - 14. Низкие значения по шкале «внутренней конфликтности» имеют 14 респондентов, по шкале «самообвинения» - 24 респондента (рисунок 1). Крайне низкие значения шкалы «самообвинения» свидетельствуют об отрицании проблем, закрытости, самодовольстве. Низкие значения по шкале «внутренней конфликтности» могут свидетельствовать о неудовлетворенности собой, об идеальном представлении себя и желании что-то в себе изменить. Таким образом, можно предположить, что студентам свойственно перекладывать ответственность на других, быть недовольными собой и окружающими, отрицать существующие проблемы.

Методика диагностики уровня эмоциональной стабильности и нестабильности личности EPQ Айзенка позволила установить, что высокий уровень нейротизма имеют 14 человек, средний - 17, низкий - 9. По шкале психотизма 8 респондентов имеют высокие показатели, 20 - средние и 12 - низкие.

На основе данных были проведены расчеты, показывающие соответствие экстраверсии и интроверсии с психотизмом и нейротизмом. В таблицу 2 не вошли средние значения по всем показателям.

Таблица 2.

Взаимосвязь экстраверсии и интроверсии с психотизмом и нейротизмом

\begin{tabular}{|c|c|c|c|c|}
\hline \multirow[t]{3}{*}{$\begin{array}{l}\text { Типы } \\
\text { респондентов }\end{array}$} & \multicolumn{4}{|c|}{$\begin{array}{c}\text { Показатели наполненности подгрупп с разным уровнем } \\
\text { нейротизма и психотизма (в\%) }\end{array}$} \\
\hline & \multicolumn{2}{|c|}{ нейротизм } & \multicolumn{2}{|c|}{ психотизм } \\
\hline & высокий & низкий & высокий & низкий \\
\hline экстраверты & 26 & 21,7 & 17 & 30,4 \\
\hline интровертьл & 80 & 20 & 20 & 0 \\
\hline
\end{tabular}

Результаты измерения, представленные в таблице 2, показывают, что нейротизму подвержены большей частью интроверты - 80\%. Экстраверты обладают нейротизмом и психотизмом примерно в равной степени (26\% и $17 \%)$.

Используя данные обследования по шкалам экстраверсия - интроверсия и нейротизм - стабильность, были выведены показатели темперамента личности по классификации Павлова, который описал четыре классических типа: сангвиник, холерик, флегматик, меланхолик и представили в виде матрицы. Строки матрицы характеризуют направленность показателей - интроверсия, средние значения, экстраверсия, а столбцы соответствуют уровням эмоциональной устойчивости (нейротизм; средние значения; стабильность), а элементы - статистически нормальный и уклоняющийся от него типы. Таким образом по методике EPQ, мы можем представить Матричную типологию личности. При таком подходе существует возможность подробного описания типов личности и присущих им характерных черт. В таблице 3 на основе матричной типологии личности был составлен «профильный» портрет респондентов (см. табл. 3)

«Профильный» портрет студентов БрГТУ можно записать в виде мультимножества типов: (4 H, 4 МХ, 11 ХC , 3 СФ, 1 ФМ, 6 Х, 6 С, 1 Ф, 4 М). Зафиксировав порядок перечисления типов, получаем одномерное статистическое распределение, которое можно сопоставить с графическим изображением в виде профиля, аналогичного известным психологическим профилям по Россолимо. Матричное и профильное порфетирование позволяет легко сравнивать типологические портреты различных социальных групп людей, а графическое изображение профилей обеспечивает наглядность при сравнении 
«Профильный» портрет студентов БрГТУ

Таблица 3.

\begin{tabular}{|l|c|c|c|}
\hline \multirow{2}{*}{\begin{tabular}{|} 
Показатели \\
\cline { 2 - 4 }
\end{tabular}} & Интроверсия & Средние значения & Экстраверсия \\
\hline Нейротизм (>16 б.) & $4 \mathrm{M}$ & $(7-15$ балл) & (>15 балл) \\
\hline Средние значения (8-16 б.) & 1 ФМ & $4 \mathrm{MX}$ & $6 \mathrm{X}$ \\
\hline Стабильность (8 б.) & $1 \Phi$ & $4 \mathrm{H}$ & $11 \mathrm{XC}$ \\
\hline
\end{tabular}

В проводимом нами исследовании проверялись гипотезы о том, что:

- во-первых, психика каждого человека использует несколько механизмов психологической защиты, причем некоторые МПЗ присущи большему количеству людей, а некоторые проявляются реже;

- во-вторых, количество МПЗ и процент их использования зависит от темперамента, внутренней конфликтности и самообвинения.

Сравнив результаты, полученные по трем методикам, можно отметить следующее, что нейротизмом обладают все исследуемые холерического (Х) и меланхолически-холерического (MX) темперамента, а также меланхолики (M). Людям с этими типологическими особенностями свойственна эмоциональная неуравновешенность. У них преобладает средняя внутренняя конфликтность и самообвинение. Самый высокий уровень ОНЗ у МХ, они используют $63 \%$ защитных механизмов. У всех присутствует регрессия, проекция и компенсация.

МПЗ оказались в соответствии с прежде проводимыми исследованиями, но по ходу работы было выявлено, что в данной выборке отсутствуют респонденты с внутренней конфликтностью. При этом данные по методике ИЖС Плутчика свидетельствуют, что более $50 \%$ респондентов имеют неразрешенные внешние и внутренние конфликты.

Общая картина полученных результатов отражает следующее:

- у холерически-сангвинического типа (XC) отсутствует «внутренняя конфликтность» и практически нет «самообвинения», при этом преобладают такие МПЗ как отрицание, компенсация и интеллектуализация;

- уровень нейротизма имеет средние значения (8-16 баллов), а уровень психотизма колеблется от 4 до 11 баллов (средний для психотизма 5-12 баллов). Людям, набравшим более 10 баллов по шкале психотизма, не рекомендуется работать по специальности «человек-человек». Активность, общительность и оптимистичность данного темперамента позволяет иметь в норме внутреннюю конфликтность при высоких показателях ПЗ.

Реактивное образование отсутствует у сангвиников (С), сангвинически-флегматического типа (СФ), холерически-сангвинического (ХC) и холериков (Х). У флегматиков (Ф) и флегматико-меланхолического типа (ФМ) отсутствует МПЗ «реактивное образование», хотя в данном случае однозначность выводов мала, по причине малочисленной выборки респондентов. Сангвиники, СФ, Ф и ФМ ищут виноватых вовне, об этом говорят низкие показатели «Внутренней конфликтности» и «Самообвинения». Максимальное количество психологических защит (63\%) используют респонденты с меланхолически-холерическим типом (MX). Абсолютное большинство из них имеют защиты - регрессия (68\%), проекция (69\%) и замещение $(71 \%)$. Только у этого типа самый высокий уровень МПЗ - реактивное образование (60\%). MX имеют самые высокие данные по нейротизму и психотизму. ОНЗ по каждой защите имеют показатели от $54 \%$ до $71 \%$. Эти данные подтверждают описание качеств, присущих данному типу: добросовестный, капризный, нейротичный, обидчивый, неспокойный. 
Респонденты с холерическим темпераментом имеют ОН3 - 55\% и у них преобладают МПЗ: компенсация (70\%), проекция (64\%), замещение $(63 \%)$ и регрессия $(62 \%)$. Отрицание они используют на $60 \%$, а интеллектуализацию на $57 \%$. У холерически-сангвинического темперамента преобладает отрицание $(62 \%)$, компенсация $(61 \%)$, проекция (59\%) и интеллектуализация (63\%). ОНЗ - 52\%. МПЗ реактивное образование используется всего на $26 \%$. Меланхолический темперамент имеет ОНЗ (56\%) и здесь преобладают ПЗ - вытеснение (63\%), регрессия (55\%), компенсация (63\%), проекция (69\%) замещение (58\%), реактивное образование (58\%). Интеллектуализацию меланхолики используют на 50\%, а отрицание на $33 \%$. Сангвинически-флегматический темперамент имеет самый низкий ОНЗ - 41\% и преобладающими защитами являются: отрицание (64\%) и интеллектуализация (72\%), поскольку обладает спокойным, уравновешенным и беззаботным характером. Сангвиники, будучи непринужденными и быстро реагирующими имеют ОН3 47\% и преобладающими МПЗ у них выступают отрицание (73\%), компенсация $(60 \%)$ и интеллектуализация (61\%). Практически не используют регрессию (26\%) и реактивное образование (22\%). С темпераментом «норма» активно используют отрицание $(60 \%)$ и интеллектуализацию (65\%) респондентов. Можно утверждать, что использование количества МПЗ и процент их использования находится в определенном соответствии с темпераментом, присущим человеку.

Поскольку объектом исследования выступали механизмы психологической защиты, и нашей задачей было рассмотреть, как они используются в зависимости от проявленности определенных характеристик личности (нейротизм, психотизм и внутренняя неустроенность), мы сопоставили полученные данные с учетом максимальных значений по шкалам психотизма и нейротизма и низкие значения по внутренней конфликтности и самообвинению. Полученные результаты в нашем исследовании мы сравнивали с другими исследованиями, поскольку у нас была только одна группа исследуемых.

Согласно структурной теории личности Келлермана, индивид может использовать любую комбинацию механизмов защиты. Первыми возникают механизмы, в основе которых лежат перцептивные процессы (ощущение, восприятие и внимание). Именно перцепция несет ответственность за защиты, связанные с неведением, непониманием информации. К ним относят отрицание и регрессию. Они являются наиболее примитивными и характеризуют «злоупотребляющую» ими личность как эмоционально незрелую. Далее возникают защиты, связанные с памятью, а именно с забыванием информации - это вытеснение и подавление.

В данном исследовании отрицание присутствует у всех исследуемых с разной напряженностью (ОНЗ по типу от $46 \%$ у меланхоликов до $73 \%$ у сангвиников, с нейротизмом - $51 \%$, с психотизмом - 59\%, с низкой внутренней конфликтностью - $58 \%$ и с самообвинением - 62\%, как первичный механизм защиты.

По мере развития процессов мышления и воображения формируются наиболее сложные и зрелые виды защит, связанные с переработкой и переоценкой информации - это рационализация. В данном случае, в одинаковом соотношении респонденты используют как первичные защиты - отрицание - 51\%-62\%, так и зрелые виды защит интеллектуализацию 54\%-64\%. Вытеснение (51\%) и регрессию (51\%) используют только респонденты с нейротизмом. Поскольку в нашем исследовании принимали участие студенты, в силу возрастных особенностей и, находясь в процессе обучения, они все используют МПЗ рационализацию. Таким образом, респонденты данной выборки используют механизмы как первичной защиты, так и зрелые виды защит.

По данным разных авторов, выраженность защитных механизмов неодинакова. У Плутчика с соавторами (PlutchiK et al., 1979) на первом месте стоит механизм интеллектуализации (63\%), за ним следуют регрессия (51\%), проекция (42\%) и компенсация (34\%). Согласно Тулупьевой (2000), наиболее выражены в ранней юности проекция (67\%), интеллектуализация (53\%) и компенсация (52\%). Бабаян (2003) выявила, что на первом месте по частоте использования у лиц молодого возраста, выбравших профессию педагога, стоит 
компенсация (57,6\%), затем следуют интеллектуализация (38\%), замещение (37\%), реактивное образование (36.2\%), вытеснение $(35,8 \%)$.

В данном исследовании ярко выраженные защиты: компенсация 60\%, отрицание, проекция и интеллектуализация по 58\%. Расхождения наших данных с другими исследователями - в процентном использовании, ранжировании. Наличие сходства заключается в наличии определенных защит, таких как компенсация, интеллектуализация и проекция и подтверждает их использование как основных механизмов психологической защиты.

Расхождения, очевидно, связаны как с возрастными, так и с индивидуальными и половыми особенностями, о чем, в частности, свидетельствуют результаты, полученные Т. В. Тулупьевой. Она показала, что с одной стороны, уровень проявления всех защитных механизмов высок у замкнутых юношей и девушек, характеризуемых выраженным индивидуализмом, тревожностью и эмоциональной неустойчивостью, а с другой стороны, у разных лиц преобладает тот или иной вид защиты и существуют черты личности, характерные для определенного защитного механизма.

Сравнительный анализ существующих точек зрения на феномен МПЗ выявил совпадения в использовании защит. Разница оказалась только в проценте использования защит, что вероятно связано с возрастными особенностями и принадлежностью к социальной группе. Сравнительный анализ не выявил существенных различий между проведенными ранее исследованиями, что подтверждает выдвинутую нами гипотезу.

В данной работе было исследовано использование МПЗ в соответствии с наличием определенного уровня нейротизма, психотизма, внутренней конфликтности и самообвинения. Следует отметить, что невротики используют МПЗ в максимально полном объеме, т.е. все защиты $(51 \%$ - 67\%), а МПЗ - «реактивное образование» используется в пределах нормы - от $24 \%$ до $43 \%$.

На второй позиции, по количеству используемых защит, определились респонденты с психотизмом. Они используют отрицание $-59 \%$, компенсацию $-63 \%$, проекцию - 55\%, замещение $-57 \%$, интеллектуализацию - 54\%. Оказалось, что все респонденты используют ЗМ «интеллектуализацию», возможно это связано с тем, что они студенты ВУЗа. Однако исследования Р. Плутчика показывают, что использование МПЗ интеллектуализация/рационализация стоит на первом месте и составляет $63 \%$. В нашем случае $-58 \%$.

В нашей работе был выявлен низкий уровень «внутренней конфликтности» и «самообвинения». Поэтому для анализа были использованы именно низкие показатели, которые говорят о том, что человек склонен отрицать свои проблемы и поверхностно воспринимать себя, отрицать свою вину в конфликтных ситуациях и переносить ее на других, порицать окружающих и считать их виновниками своих проблем. Обращает на себя внимание следующий факт, что в процессе эмпирического исследования в данной группе респондентов практически все имеют низкие показатели по внутренней конфликтности и самообвинению.

На первоначальном этапе исследования этот момент не привлек нашего внимания, но при проведении обобщающего анализа, нами был сделан вывод о том, что полученные данные по низким уровням «внутренней конфликтности» и «самообвинения» свидетельствуют в пользу необходимости проведения специальных мероприятий для студентов. Согласно данных исследования у студентов отсутствует самообвинение и этот показатель служит предостережением. Этот факт указывает не на ситуацию, характеризующуюся разрушением себя за счет самообвинения, а аспект, при котором человек вообще ответственность за любые события делегирует только окружающим, освобождая себя полностью от ответственности. Идет ориентация вовне, нет виденья себя, осознания и понимания своего внутреннего мира, нет желания и мотивации брать на себя ответственность. Они спокойно используют психологические защиты и используют их с «умом» (интеллектуализация и рационализация). При этом внутренний потенциал для развития отсутствует. Это одна из задач, которую необходимо решать. Это та самая ответственность, которой не хватает, когда случаются непоправимые события, 
происходящие по вине так называемого «человеческого фактора». Именно перенос ответственности на «другого» позволяет допускать оплошности, ошибки, причем серьезные, такие как смерть других людей.

Выводы. Мы полагаем, что исследование внутреннего потенциала человека на уровне психологических защит является весьма перспективным, так как именно во внутренних ресурсах, в умении их использовать осознанно ключ к решению многих общечеловеческих проблем и вопросов.

\section{СПИСОК ССЫЛОК:}

Агарков, В.А., Бронфман, С.А. (2009) Взаимосвязь свойств темперамента и механизмов психологической защиты. Журнал Практической Психологии и Психоанализа,4, $164-184$. Центр.

Айзенк, Г.Ю., Вильсон Г. (2000) Как измерить личность. Москва: ООО Когито-

Деларю, В.В. (2004) Защчитные механизмы личности. Волгоград: ВолгГАСА.

Карвасарский, Б.Д. (2004) Клиническая психология. Санкт-Петербург: Питер.

Козырев, Г. И. (2008) Политическая конфликтология: учебное пособие. Москва ИД «ФОРУМ»: ИНФРА-М.

Кружкова. О.В., Шахматова. О.Н. (2006) Психологические защиты личности. Екатеринбург: Издательство Росгоспрофпедуниверситет.

Никольская, И.М., Грановская, Р.М. (2011) Психологическая защита у детей. СанктПетербург: Речь.

Пантилеев, С.Р. (1993) Методика исследования самоотношения. Москва: СМЫСЛ.

Пантилеев, С. Р.(2000) Самоотношение Психология самосознания. Самара: БАХРАХ-

M.

Перре, М., Бауман, У. (2007) Клиническая психология. Санкт-Петербург: Питер.

Ковалев, П. Д. (2013) Самообвинение. Взято с https://podskazki.info/samoobvinenie.

Практическая психодиагностика. Методики и тесты. Учебное пособие (2001). Самара: Издательский. Дом «БАХРАХ-М». ISBN 5-89570-005-5.

Психология и психиатрия (2020). Взято с [http://psihomed.com/neyrotizm/]. Бахрах M.

Райгородский, Д.Я. Самосознание и защчитные механизмы личности (2000). Самара:

Фетискин, Н.П., Козлов, В.В., Мануйлов, Г.М. (2002) Социиально-психологическая диагностика развития личности и мальхх групп. Изд-во Института Психотерапии.

Фрейд, А. (1993) Психология «Я» и защитныле механизмы. Москва: Педагогика-Пресс.

\section{REFERENCES:}

Agarkov, V.A., Bronfman, S.A. (2009) Vzaimosvyaz' svojstv temperamenta i mekhanizmov psihologicheskoj zashchity. [Relationship between the properties of temperament and mechanisms of psychological protection]. ZHurnal Prakticheskoj Psihologii i Psihoanaliza, 4, 164-184.

Ajzenk, G.YU., Vil'son G. (2000) Kak izmerit' lichnost'. [How to measure personality]. Moskva: OOO Kogito-Centr.

Delaryu, V.V. (2004) Zashchitnye mekhanizmy lichnosti. [Personal Protection Mechanisms]. Volgograd: VolgGASA.

Karvasarskij, B.D. (2004) Klinicheskaya psihologiya. [Clinical psychology]. SanktPeterburg: Piter.

Kozyrev, G. I. (2008) Politicheskaya konfliktologiya: uchebnoe posobie. [Political Conflict: training manual]. Moskva ID «FORUM»: INFRA-M.

Kruzhkova. O.V., Shahmatova. O.N. (2006) Psihologicheskie zashchity lichnosti. [Psychological Protection of the Person]. Ekaterinburg: Izdatel'stvo Rosgosprofpeduniversitet.

Nikol'skaya, I.M., Granovskaya, R.M. (2011) Psihologicheskaya zashchita u detej. [Psychological protection in children]. Sankt-Peterburg: Rech'. 
Pantileev, S.R. (1993) Metodika issledovaniya samootnosheniya. [Method of investigation of self-destruction]. Moskva: SMYSL.

.Pantileev, S. R. (2000) Samootnoshenie Psihologiya samosoznaniya. [Self-respect Psychology of Self-awareness]. Samara: BAHRAH-M.

Perre, M., Bauman, U. (2007) Klinicheskaya psihologiya. [Clinical psychology]. SanktPeterburg: Piter.

Kovalev, P. D. (2013) Samoobvinenie. [Self-incrimination]. Vzyato s https://podskazki.info/samoobvinenie.

Prakticheskaya psihodiagnostika. Metodiki i testy. Uchebnoe posobie. [Practical Psychodiagnostics. Methodologies and Tests. Teaching Manual]. (2001). Samara: Izdatel'skij. Dom «BAHRAH-M». ISBN 5-89570-005-5.

Psihologiya i psihiatriya. [Psychology and Psychiatry]. (2020). Vzyato s [http://psihomed.com/neyrotizm/].

Rajgorodskij, D.Ya. Samosoznanie i zashchitnye mekhanizmy lichnosti. [Self-awareness and protective mechanisms of the individual]. (2000). Samara: Bahrah-M.

Fetiskin, N.P., Kozlov, V.V., Manujlov, G.M. (2002) Social'no-psihologicheskaya diagnostika razvitiya lichnosti i malyh grupp. [Socio-psychological diagnosis of personality development and small groups]. Izd-vo Instituta Psihoterapii.

Frejd, A. (1993) Psihologiya «Ya» i zashchitnye mekhanizmy. [Psychology «Ya» and protective mechanisms]. Moskva: Pedagogika-Press.

\title{
PECULIARITIES OF THE PERSONALITY'S SELECTION OF PROTECTIVE MECHANISMS
}

\author{
Svetlana Yashchuk \\ Candidate of Psychological Sciences, Associate \\ Professor of the Department of Psychology \\ Brest State University named after A. S. Pushkin \\ ORCID: 0000-0002-5886-6136 \\ DOI https://doi.org/10.35619/praprv.v1i15.200
}

\begin{abstract}
The materials of this article are devoted to the strategy of choosing protective mechanisms by a person in accordance with the peculiarities of the manifestation of such personal characteristics as neuroticism, psychoticism, internal conflict, self-attitude. Based on the analysis of the mechanisms of psychological protection used by students of the technical university and their characteristic manifestations of personal characteristics, the prevailing strategies for using protective mechanisms are identified. Based on the analysis of the obtained data it was established that the psyche of each person uses several psychological defense mechanisms, and some mechanisms of psychological protection inherent in many people, and some occur less frequently, while the number of psychological defense mechanisms and the percentage of their use depends on the temperament, inner conflict and self-blame. In the study, it was found that all respondents are characterized by neuroticism. It was found that neurotics use MPZ to the fullest extent possible. Respondents with psychoticism use them less. All respondents use the defense mechanism "intellectualization", which refers to more mature defense mechanisms. This study revealed a low level of" internal conflict "and"self-blame". The results obtained allow us to expand the scope of psychological education and prevention with young people in the context of awareness and understanding of "personal" resources.
\end{abstract}

Key words: psychological defense mechanisms, defense mechanisms, psychological defense, personality, emotional stability, temperament, self-attitude, neuroticism. 